\title{
Dos paratextos como "protocolos de leitura" na tradução de clássicos: o caso de Romeu e Julieta (1940)
}

The paratexts as "reading protocols" in the translation of classics: the case of Romeo and Juliet (1940)

Henrique Brener Vertchenko ${ }^{1}$ 


\section{Resumo}

Tendo como fontes primordiais a Introdução e as Notas da primeira tradução brasileira em livro de Romeu e Julieta, feita por Onestaldo de Pennafort e publicada em 1940 por iniciativa do Ministério da Educação e Saúde, este artigo discute o sentido e as estratégias desses paratextos editoriais no seio de um projeto estatal de tradução de clássicos do teatro. A partir desse estudo de caso, objetiva-se demonstrar como paratextos podem atuar de maneira contundente como protocolos de leitura, configurando-se como escritos que podem orientar a experiência de leitura de traduções, operando como dispositivos mediadores nesse complexo processo.

Palavras-chave: Romeu e Julieta; Onestaldo de Pennafort; Tradução teatral; $\mathrm{Pa}$ ratextos editoriais; Protocolos de leitura

\section{Abstract}

Having as main sources the Introduction and the Notes of the first Brazilian translation in book of Romeo and Juliet, made by Onestaldo de Pennafort and published in 1940 by initiative of the Ministry of Education and Health, this article discusses the meaning and the strategies of these editorial paratexts in a state project of translation for theatre classics. From this case study, we aim to demonstrate how paratexts can act in a forceful way as reading protocols, being configured as writings that can guide the experience of reading translations, operating as mediating devices in this complex process.

Keywords: Romeu and Juliet; Onestaldo de Pennafort; Theatrical translation; Editorial paratexts; Reading protocols 
A Comissão de Teatro Nacional, instituída por portaria datada de 14 de setembro de 1936, e atuante até o fim de 1937, quando seria substituída pelo Serviço Nacional de Teatro, foi formada por Múcio Leão, Oduvaldo Vianna, Francisco Mignone, Sérgio Buarque de Holanda, Olavo de Barros, Benjamin Lima, Oscar Lorenzo de Fernandes e Celso Kelly², que se reuniam em sessões semanais e extraordinárias, algumas presididas pelo próprio Ministro Gustavo Capanema ${ }^{3}$. Dentre um dos três objetivos da atuação da Comissão estava:

a) promover estudos sobre o teatro, tornando-se um órgão técnico em todos os assuntos que lhe dissessem respeito e preparando para isso, através de inquéritos, publicações e estudos especiais, uma documentação completa do que se tem produzido e do que se pode fazer em teatro. (O Governo e o Teatro, 1937, p. 6)

Percebe-se nesse objetivo, ao mesmo tempo, o intuito de diagnóstico e de projeto para o futuro. Assim, a Comissão identificou alguns pontos no que tange ao "problema da produção intelectual em matéria de teatro", chegando às conclusões de que era "a) relativamente pouco numerosa a produção teatral brasileira"; "b) não estar essa produção impressa na sua totalidade"; "c) haver dificuldade de obter editores para peças de teatro"; "d) ser pouco conhecido, em nosso meio, o teatro estrangeiro, do clássico ao contemporâneo" e "e) experimentar-se grande dificuldade na organização de repertórios, como consequência das conclusões anteriores". (O Governo e o Teatro, 1937, p. 12-13)

Para suprir essas adversidades, a Comissão decidiu-se pela promoção da publicação de uma Coleção Brasileira de Teatro, compreendendo um planejamento de peças dramáticas escritas em língua portuguesa; traduções de peças dramáticas do teatro universal; obras de teatro lírico, musicado e coreográfico, contendo músicas e textos; e estudos sobre teatro, como história, crítica, arquitetura e cenografia. Para tal, foi encomendada a J. Santos Júnior uma bibliografia completa das obras dramáticas brasileiras e portuguesas escritas ao longo da história 4 . As publicações em língua portuguesa seriam selecionadas para a Coleção a partir dessa bibliografia e pela instituição de prêmios a autores brasileiros de então.

A escolha da série de obras estrangeiras a serem traduzidas e publicadas mereceu cuidado especial, decidindo-se, inicialmente, pela seleção de vinte "grandes" peças. Para tanto, o Ministro Capanema mandou a um grande número de intelectuais do país uma circular com os seguintes dizeres:

Com o objetivo de estimular a formação de um ambiente propício ao desenvolvimento da arte dramática no Brasil, a Comissão de Teatro Nacional, entre outras iniciativas, resolveu promover esta de tornar conhecidas do grande público as melhores obras de teatro que já se escreveram.

\footnotetext{
2 Angélica Ricci Camargo levanta a hipótese de que a formação da Comissão obedeceu a critérios diversos. A despeito de todos possuírem, em graus muito variados, projeção nos campos intelectual e artístico e de a maioria já ter ocupado cargos na administração pública, somente três eram ligados diretamente ao teatro: um representante indicado pela classe (Olavo de Barros, presidente da Casa dos Artistas), um dramaturgo de projeção ligado à SBAT (Oduvaldo Vianna) e um representante da crítica (Benjamin Lima). (Camargo, 2011)

3 Segundo o folheto: O Govêrno e o Teatro. (folheto) Rio de Janeiro: Serviço Gráfico do Ministério da Educação e Saúde, 1937. As informações que se seguem foram publicadas nesse folheto.

4 Até o momento, não foi possível descobrir se essa bibliografia foi executada.
} 


\begin{abstract}
Foi, assim, julgado conveniente fazer, desde logo, a tradução, em língua portuguesa, das obras que possam constituir a base de uma biblioteca brasileira de teatro universal.

Para a escolha dessas obras, opina a Comissão Nacional de Teatro, que nenhum processo será mais adequado e seguro do que organizar-se um inquérito entre os nossos intelectuais mais autorizados para falar sobre o assunto.

Com tal intuito, foi redigida a presente circular que tenho o prazer de remeter a V. Excia., pedindo-lhe a sua resposta, que, estou certo, representará uma contribuição significativa para a preparação da projetada coleção. (O Governo e o Teatro, 1937, p. 14)
\end{abstract}

Em seguida, a circular apresentava o inquérito, perguntando, dentre as obras de teatro (tragédias, comédias, etc.) de todos os tempos e em todos os idiomas (exceto o português), quais as vinte que poderiam ser apontadas como obras primas da literatura universal, terem sentido universal e humano e serem capazes de despertar interesse no grande público ${ }^{5}$.

Esta carta foi enviada a mais de cem intelectuais, e, segundo o folheto O Governo e o Teatro, responderam: Ramiz Galvão, Onestaldo de Pennafort, Xavier Marques, Tristão da Cunha, Afonso de E. Taunay, Rodrigo Melo Franco de Andrade, Lúcio José dos Santos, Álvaro Moreyra, Vinícius de Moraes, Plinio Barreto, Cassiano Ricardo, Raul Bittencourt, Abgar Renault, Roquette Pinto, Oswald de Andrade, Jorge de Lima, Antenor Nascentes, Elmano Cardim, Murilo Mendes, Manuel Bandeira, Peregrino Junior, Gustavo Barroso, Sousa da Silveira, Raul Pedroza, Conde de Afonso Celso, Luiz Martins, Eurialo Canabrava, Pe. J. de Castro Nery e Jorge de Castro6.

A apuração do inquérito elegeu 23 obras, listadas aqui em ordem decrescente de votos: O Cid, de Corneille (19 votos); Hamlet, de Shakespeare (18 votos); Fausto, de Goethe (15 votos); Tartufo, de Molière (14 votos); Atalia, de Racine (12 votos); Fedra, também de Racine (11 votos); Romeu e Julieta, de Shakespeare (10 votos); O Misantropo, de Molière (10 votos); Seis Personagens à procura de um autor, de Pirandello (10 votos); Antígona, de Sófocles (9 votos); Otelo, de Shakespeare (9 votos); Macbeth, de Shakespeare (9 votos); Édipo Rei, de Sófocles (9 votos); Prometeu Acorrentado, de Ésquilo (8 votos); A Gioconda, de D Annunzio (8 votos); Rei Lear, de Shakespeare (8 votos); Os Espectros, de Ibsen (8 votos); Knock, de Jules Romain (7 votos); Santa Joana, de Bernard Shaw (7 votos); O Avarento, de Molière (7 votos); Henrique IV, de Pirandello (7 votos); A Vida é Sonho, de Calderón de la Barca (7 votos) e O Doente Imaginário, de Molière (7 votos).

Receberam ainda de três a seis votos: Cyrano de Bergerac, de Edmond Rostand; O Barbeiro de Sevilha, de Beaumarchais; Guilherme Tell, de Schiller; Solness, o construtor, de Ibsen; Hernani, de Victor Hugo; Andromaca, de Racine; Julio Cesar, de Shakespeare; Hedda Gabler, de Ibsen; As Nuves, de Aristófanes; Casa de Bonecas, de Ibsen; Peer Gynt, também de Ibsen; Eumênides, de Ésquilo; A Anunciação, de Claudel; A cidade morta, de D’Annunzio; O mercador de Veneza, de Shakespeare; $O$ burlador de Sevilha, de Tirso de Molina; O Imperador Jones, de Eugene $O$ 'Neill; $O$ es-

\footnotetext{
5 Segundo Camargo, 2011, a primeira versão da circular incluía também o quarto item "possuir valor educativo", que acabou sendo suprimido.

6 A Comissão de Teatro Nacional promete a publicação das respostas desses intelectuais compondo um volume na série de estudos sobre teatro da Coleção Brasileira de Teatro, publicação esta que não foi encontrada.
} 
tranho entremez, também de O'Neill; O burguês gentilhomem, de Molière; O pássaro azul, de Maurice Maëterlinck; Pelléas e Melisande, também de Maëterlinck; Crime e Castigo, de Gaston Baty; Wallenstein, de Schiller; e Ifigênia em Áulide, de Eurípides.

Apesar de não ter sido a mais votada no inquérito, a primeira tradução escoIhida para compor a Coleção foi a de Romeu e Julieta, encarregada a Onestaldo de Pennafort. Entretanto, a sua publicação só foi levada a cabo em 1940, ou seja, três anos após o inquérito, em edição do Ministério da Educação e Saúde, com capa e ilustrações - incluídas aí vinhetas e iluminuras - de Tomás Santa Rosa, 217 páginas, encadernação em couro e uma tiragem de 2030 exemplares, sendo 30 especiais, fora de comércio. Tratava-se, de fato, da primeira publicação de uma tradução brasileira da peça de Shakespeare ${ }^{7}$, evento a ser celebrado.

Poeta tido como derradeiro simbolista, Pennafort (Bandeira, 1966) publicara diversos livros de poesia na década de 1920, colaborava com diversos periódicos, entre eles Fon-Fon, Careta e Para Todos, já havia realizado a tradução de Festas Galantes, de Paul Verlaine, pela Cia Editora Nacional em 1934,8 e é encarregado de uma tarefa que se torna um ato literário. Traduzido do inglês segundo o texto da respeitada edição da Arden, o Romeu e Julieta de 1940 chama a atenção pelas suas longas Introducção e Notas, possuindo, a primeira, cinco páginas, e, a segunda, 74. Podemos definir essas estruturas como paratextos editoriais, que, segundo Genette (2009, p. 9), são

[...] certo número de produções, verbais ou não, com um nome de autor, um título, um prefácio, ilustrações, que [...] o cercam [o texto] e o prolongam, exatamente para apresentá-lo, no sentido habitual do verbo, mas também em seu sentido mais forte: para torná-lo presente, para garantir sua presença no mundo, sua 'recepção' e seu consumo, sob a forma, pelo menos hoje de um livro.

Assim, se temos as vinhetas de Santa Rosa ornamentando a separação entre os atos, trazendo ao mesmo tempo imponência e leveza à leitura, as informações na Introducção e nas Notas se apresentam como paratextos elucidativos e privilegiados para a percepção da apropriação do texto no ato tradutório. Elas revelam esse ato como um processo de estudo sobre o autor, sua linguagem e seu tempo, e permitem perceber como esses escritos podiam, potencialmente, direcionar ou interferir na experiência de leitura de traduções, atuando como mediadores nesse complexo processo.

Isso significa dizer que paratextos podem atuar de maneira contundente como protocolos de leitura. Segundo Chartier (1996, p. 78), é fundamental

[...] pensar que os atos de leitura que dão aos textos significações plurais e móveis situam-se no encontro de maneiras de ler, coletivas ou individuais, herdadas ou inovadoras, íntimas ou públicas e de protocolos de leitura depositados no objeto lido, não somente pelo autor que indica a justa compreensão de seu texto, mas também pelo impressor que compõe as formas tipográficas, seja com um objetivo explícito, seja inconscientemente, em conformidade com os hábitos de seu tempo. (grifo nosso)

\footnotetext{
7 A tradução de Pennafort foi utilizada ao menos em duas importantes montagens de Romeu e Julieta: a do Grupo Galpão, com direção e concepção de Gabriel Villela, em 1992; e a do Teatro do Estudante do Brasil (TEB), em 1949. Na primeira montagem do TEB, em 1938, fora usada a tradução portuguesa de Domingos Ramos. (Fontana, 2014)

8 Pennafort ainda faria, em 1956, a tradução de Otelo, pela Civilização Brasileira (Shakespeare, 1956).
} 
São assim, espécie de instruções que objetivam garantir uma relação "correta" com o texto e apontar seus sentidos, ou, um conjunto de dispositivos que aproximam o leitor de certas maneiras de ler e, no caso de nosso objeto, de situar essa peça no quadro da dramaturgia e da literatura mundiais, fazendo o leitor compreender a importância patriótica da iniciativa.

Ao considerarmos esses dispositivos fundamentais, sobretudo na observação de atos tradutórios em seus atributos de recriação, objetivamos, a partir de então, discutir a maneira pela qual Pennafort compõe esses paratextos. Eles permitem entrever as características do projeto editorial empreendido pelo Ministério da Educação e Saúde, assim como novos horizontes para o campo da tradução teatral a partir da década de 1940.

\section{A Introducção}

A Introdução de Pennafort se alicerça em dois eixos principais, a saber, a iniciativa do Ministério da Educação e a justificativa para que sua tradução fosse realizada mantendo as passagens em que Shakespeare escreveu em versos. Sobre o primeiro desses eixos, diz, abrindo seu texto:

A presente traducção desta obra prima, chronologicamente a primeira tragedia de Shakespeare, obra, portanto, em que palpita todo o lyrismo e todo o ardor da mocidade, foi por mim realizada por imcumbencia do Sr. Ministro Gustavo Capanema, o qual, na sua patriotica gestão no Ministerio da Educação e Saude, entre tantas outras iniciativas felizes e de caracter eminentemente cultural, que o recomendam à gratidão e à admiração do paiz, tem dedicado o melhor do seu esforço em prol do levantamento do theatro nacional como factor e a um tempo expressão de cultura. (Pennafort, 1940, p. 11)

Enaltece, assim, o inteligente programa do Ministro para com o teatro, que, sob os auspícios do presidente Vargas, cogitou tornar possível no Brasil a representação de grandes peças do teatro universal, graças à "mercê" de traduções fiéis.

Pennafort argumenta que o trabalho foi feito, apesar de poder servir a finalidades didáticas, "principalmente para o theatro, o que vale dizer, com um objectivo artistico" (1940, p. 12), tendo buscado produzir um texto encenável e com naturalidade de expressão, já que traduzir Shakespeare em linguagem excessivamente rebuscada ou literária seria, em determinado sentido, uma traição. Percebe-se, desde já, a crença implícita acerca do objetivo dessa iniciativa - a encenação. Isso possibilita, igualmente, a sugestão de quais seriam os leitores e tipo de leitura presumidos da obra. Se por um lado o livro possui certo luxo e ares celebratórios proporcionados pela iniciativa estatal, por outro, se evidenciam os objetivos de popularização e de que a tradução ganhe os palcos.

No que se refere à popularização, ela é abordada quando o tradutor descreve o inquérito realizado pelo Ministério, que deveria apurar quais as vinte peças, "de todos os tempos e de todos os idiomas" (Pennafort, 1940, p. 12), que, somado aos requisitos de serem obras primas incontestáveis e de terem sentido humano e universal, fossem capazes de despertar o interesse do grande público. Sugere, então, que talvez tenha 
sido o quesito popularidade o fator que tenha levado o Ministério a começar o empreendimento das traduções por Romeu e Julieta - lembrando, aqui, que essa não havia sido a peça mais votada no inquérito. Faz, em seguida, uma defesa apaixonada da peça, legitimando seu ato:

[...] a mais popular, a mais comprehensivel em todas as latitudes, na qual extravaza a mais simples, a mais popular e comprehensivel das paixões humanas, o amor, o amor espontaneo, impulsivo, avassallador, exclusivista, que vence todas as contingencias, que triumpha da vida e das convenções sociais, que nasce de um olhar e não morre nunca, porque, segundo a Biblia, é mais forte do que a morte. (Pennafort, 1940, p. 12)

Pennafort demonstra grande interesse acerca do exercício de traduzir, oferecendo explicações que informam sobre o sentido que o próprio tradutor atribui à sua atividade, qual seja, o de uma espécie de cocriação. Nessa "tão grata quanto honrosa tarefa", que o permitiu contribuir para obra de "elevada significação patriótica" (1940, p. 12), ele pode se aproximar do espírito imortal que é Shakespeare. Dada a magnitude do autor inglês, ele assume que a sua tradução proporciona somente uma impressão do original. Isso não significa, para ele, infidelidade.

Apesar de justificar que não entrará na explicação técnica do trabalho, o que será feito largamente nas "Notas" ao fim do volume, é em longa passagem acerca da escolha da tradução em versos que Pennafort legitima sua fidelidade à obra. Defende que era forçoso manter a mesma forma do original, ou seja, a alternância entre prosa e verso sob a qual se apresentam todas as peças de Shakespeare. Esta condição não seria secundária ou dogmaticamente impraticável, mas fundamental, sendo os tradutores em prosa de Shakespeare e de outros autores do gênero portadores de argumentos ilusórios ao professarem que toda tradução em versos é necessariamente infiel. Diante disso que identifica como "conceito errôneo", Pennafort busca provar o contrário - que é preciso se traduzir em verso para se traduzir fielmente. $\mathrm{E}$ isso se deve ao fato de que, diferentemente da prosa, "[...]tem a forma poetica uma condensação expressional, determinada pela medida, que não só é impossivel transportar-se para a prosa, como seria a propria negação da finalidade e dos fundamentos desta" (1940, p. 13). Além disso, os efeitos do gênero ultrapassariam a forma, imprimindo ao texto uma vida e um sentido peculiares, o que se relacionaria ao fato de o pensamento expresso em verso ser um fenômeno diferente da operação cotidiana do espírito.

Desse modo, a condensação, a "economia expressional creadora do elemento imponderavel do texto, que é tudo na obra de arte" (Pennafort, 1940, p. 14) desapareceria se a tradução tivesse sido feita em prosa. Fundamentando esse argumento, Pennafort lança mão das palavras de Paul Stapfer, aquele que seria um dos maiores comentadores e estudiosos de Shakespeare, autor de obra monumental sobre o bardo ${ }^{9}$ :

Quando se trata de um poeta, o brilho, o movimento, a harmonia, numa palavra, a belleza da forma tem qualquer cousa de não menos sagrada que o sentido; não conheço peor infidelidade do que a dessas traducções em prosa titubeante e ar-

9 Trata-se, segundo referência do próprio Pennafort, de Paul Stapfer. Shakespeare et l`Antiquité. Paris: Sandoz et Fischbacher, 1879. 
rastada que, sob o pretexto de verter, palavra por palavra, todas as idéas, todos os matizes do original, fazem crer ao leitor, pelo seu máo estylo, que Shakespeare é pesado e Sophocles diffuso. (Pennafort, 1940, p. 14.)

Assim, para o tradutor, o verso não seria uma fôrma pré-existente à qual o poeta ajusta sua criação, mas a expressão direta, necessária e única do seu pensamento, sendo parte fundamental do texto e conferindo-lhe vida própria e sentido. Posto isso, Pennafort argumenta, enfim, que para se traduzir fielmente uma obra em verso é necessário que o tradutor se "submetta à mesma disciplina de composição sob a qual nasceu a obra original" (1940, p.14).

A longa justificativa para a tradução em versos gravita em torno da firme crença do tradutor de que só assim é possível dar uma impressão, ainda que diluída, da qualidade do teatro shakesperiano. A sua escolha, certamente legítima, se apresenta como uma espécie de defesa diante de possíveis acusações de infidelidade quanto à literalidade da tradução e acaba por informar, nessa Introducção, a postura de um tradutor que se resguarda como fiel à forma lírica do texto e se apresenta como mediador cuidadoso. Evidentemente, não se pode esquecer que essa tradução - realizada supostamente, de acordo com as datas que encerram o texto, entre abril e setembro de 1937 - foi obra de um poeta.

Os dois eixos principais dessa Introducção, como dito anteriormente, o enaltecimento da iniciativa do Ministério da Educação e a defesa de uma tradução em versos, podem orientar a leitura, atuando como protocolos ao indicarem significados para a publicação, empreendida pelo Estado imbuído de um espírito patriótico para o teatro e feita de maneira segura e justificada por um tradutor cioso dos seus procedimentos e de seu papel. É nas "Notas", ao final do volume, que Pennafort aprofunda a explanação de seus métodos e constrói um amplo substrato para formar um pensamento sobre Romeu e Julieta e seu famoso autor.

\section{As Notas}

Ao longo de 74 páginas, as Notas de Romeu e Julieta - que, somadas à Introdução constituem quase um terço do volume - são divididas em "As fontes"; "As edições"; "O texto"; "A forma"; "A tradução"; "A scena"; "Dramatis Personae"; além das notas explicativas específicas que aparecem ao longo dos atos. Esse conjunto forma quase um tratado histórico, bibliográfico e linguístico sobre a obra.

Na primeira parte, "As fontes", Pennafort levanta as possíveis referências que levaram Shakespeare a escrever a história dos dois amantes de Verona, desde um suposto acontecimento histórico em 1303, aos primeiros relatos escritos, a apropriações, citações e traduções. Reproduzimos aqui um trecho para demonstrar como o tradutor esboça uma interessante circularidade e mobilidade do suposto tema inspirador:

A historia dos infelizes amantes de Verona, como supposto acontecimento historico, é referida no anno 1303, não existindo porém, relato anterior ao de Luigi da Porto, por volta de 1530 . Uma historia de certo modo semelhante é narrada na 
Ephesiaca, de Xenophonte de Epheso, um romanceiro grego da Idade Media, e uma outra, semelhante na substancia, em torno da aventura de Mariotto e Gianozza de Siena, se encontra numa collecção de novellas de Mascuccio de Salerno, de 1476. Mas Luigi da Porto é o primeiro a nomear Romeu e Julieta e a faze-los filhos das duas familias rivaes de Verona. A historia alcançou, de prompto, uma celebridade européa. Alterando-lhe o nome e algumas particularidades, Adrian Sevin a reconta por 1542 e Gherardo Borderi a põe em oitava rima para os seus leitores de Veneza. Bandello, refundindo em parte a narrativa, torna a conta-la na sua collecção de novellas, em 1554, e Pierre Boisteau traduz para o francês, em 1559, o italiano de Bandello, e de novo refunde a historia. Tres annos depois, toca esta a terra inglesa. Arthur Brooke, ou Broke, em 1562, publica a sua longa versão metrificada, fundada na novella de Boisteau e uma traducção em prosa da Histoire de Deux Amans, de Boisteu, apparece no Palace of Pleasure, de Painter, em 1567. Em 1594-96, isto é, na época mais ou menos em que Shakespeare escrevia a sua tragedia, Girolano de la Corte publica na Italia a sua Historia de Verona, em que recorda como facto historico o caso dos dois amantes infelizes, dando-o como ocorrido em 1303, sob o governo de Bartholomeo della Scala. Essas são as fontes de Shakespeare. (Pennafort, 1940, p. 203)

A dinâmica apresentada é baseada em constantes apropriações e fusões, próprias do período em questão. Com esse breve mapeamento, baseando-se em comparações de nomes de personagens e topônimos, assim como no Shakespeare Manual de 1878, escrito por F. G. Fleay, Pennafort começa as suas Notas buscando as origens e guiando de maneira arqueológica a imaginação do leitor.

Em seguida, em "As edições", são apresentadas as primeiras edições de Romeu e Julieta, desde os cinco Quartos, publicados em 1597, 1599, 1609, um sem data e 1637; passando pelo Folio I, reunindo todas as peças do autor em 1623; pelo Folio II, de 1632; pelo Folio III, de 1663 e 1664; e pelo Folio IV de 1685; além da fac-simile do Folio I em 1876. Apesar de não se deter nas especificidades dessas edições, Pennafort demonstra conhecimento de suas particularidades ao citar, por exemplo, as casas editoriais e dizer que, nos Quartos e no Folio I, Romeu e Julieta não apresentava divisões em atos e cenas.

Em "O texto", Pennafort esclarece a proveniência de sua tradução: "O texto de que nos servimos para a presente traducção é o da edição Arden, com as notas e estudos do eminente shakesperiano Edward Dowden e actualmente tida como a edição standard do grande poeta, a ultima palavra [...]" (Pennafort, 1940, p. 205). Desse modo, é garantida a procedência de seu original, apoiado no Quarto de 1599, aquele que seria o "mais autorizado", sem se abrir mão, contudo, do cotejamento com outras edições.

Na parte seguinte, "A forma", é apresentada de forma direta, mas minuciosa, aspectos da metrificação do texto. A partir da reafirmação de que foi escrito em prosa e verso, com passagens abruptas de uma forma para outra, são trazidos dados quantitativos acerca dos versos, detectada a presença de sonetos, apontada a dinâmica das rimas que é até mesmo comparada à de outras peças de Shakespeare, sendo Romeu e Julieta uma de suas peças com o maior número delas.

Em "A tradução", Pennafort reafirma sua perspectiva em relação ao seu trabalho e oferece importante fonte a respeito de sua autoimagem:

Foi nosso escôpo [...] extrahir da peça original, com absoluta fidelidade ao texto, 
a belleza da trama dramatica, a verdade dos caracteres, a realidade das scenas e a poesia dos versos e dos sentimentos. Procurámos para isso uma linguagem facil, acessivel, familiar, de accôrdo com a natureza das personagens e que, exceptuados certos trechos de preciosismo intencional e outros em que se sente a moeda paga ao estylo do tempo, é a linguagem de Shakespeare, autor eminentemente popular na sua época. (1940, p. 206)

E segue afirmando que traduzi-lo em linguagem afetada ou literária pode ser uma desculpa para um mal compreendido horror ao anacronismo, um apego à nobreza de estilo, e constitui uma traição. Esse apego se justificaria em traduções de Corneille ou Racine, em que as personagens são hieráticas e afastadas do cotidiano, mas não em Shakespeare, onde as personagens são vivas, reais, humanas e espontâneas, guiadas por paixões pessoais e não por conflitos morais. Chama a atenção aqui a oposição entre Shakespeare e o teatro do classicismo francês, oposição esta que possui grande lastro desde o romantismo alemão (Süssekind, 2008), e que contrasta a paixão, a liberdade criadora, a genialidade inspirada do primeiro, ao racionalismo, contenção e obediência a regras no segundo.

A defesa de um Shakespeare popular tem um reflexo prático apresentado de maneira direta nesse momento das Notas. Para trazer a naturalidade e a verdade dos diálogos, Pennafort optou por não utilizar, no caso de personagens íntimos, a segunda pessoa do plural no tratamento, como seria usual em traduções do gênero. Dessa maneira, entre a Ama e Julieta, Mercucio e Romeu, o Sr. Capuleto e seu criado, foram adotadas as "formas bem brasileiras" senhor e você, além de, por vezes, a segunda pessoa do singular, sendo estas "as unicas que dariam a um espectador brasileiro a impressão da realidade" (1940, p. 207). Justifica ainda, a manutenção de palavras pesadas e expressões livres, citando Camillo Castello Branco: "quem quizer transplantar Shakespeare para a sua lingua, e não quizer ou não souber imitar e respeitar a selvageria dessas phrases, abstenha-se da empresa temeraria" (1940, p. 207). Vale dizer que, além desses aspectos, nessa parte Pennafort tece comentários acerca de métrica, rimas, sua escolha pela alternância entre versos decassílabos e alexandrinos, suas propostas na transposição da versificação shakesperiana para o português, demonstrando rigor e conhecimento de mecanismos poéticos.

Em "A scena", o tradutor pinta um quadro ideal para a imaginação (ou a representação), tecendo uma atmosfera italiana nos dias inflamáveis de julho, que fervem o sangue nas ruas e tornam as noites de luar voluptuosas. No mesmo ardor lírico que atribui às personagens, ele descreve a escalada das ações como uma tempestade uma guerra civil, um baile, golpes de espada, um balcão - "um desses balcões que bastam para fazer imaginar uma cidade do norte da Italia" (Pennafort, 1940, p. 208) -, um jardim, uma janela onde se trocam juras de amor, um velho monge que protege os namorados, um assassinato, um desterro, o casamento em meio ao funeral, em suma, "essa serie de enganos lamentaveis que custam duas vidas jovens e conduzem os seus breves amores de uma noite de dança a um tumulo" (1940, p. 209). Diante desse movimento, era imperioso estudar o ritmo da peça, como os monólogos se equilibram e se respondem a cada ato, gerando um longo duo de amor cujos ápices são a dupla cena do balcão - as juras noturnas e a despedida no alvorecer. O modo como Pennafort constrói essas imagens e faz sugestões estéticas é exemplar da ma- 
neira como paratextos podem atuar como protocolos de leitura. A sua descrição da atmosfera, do movimento geral das ações, da localização espacial - até mesmo imaginando um balcão do norte da Itália -, o apontamento de quais para ele são as cenas chave, configuram, inevitavelmente, uma determinada maneira de se ler a peça. $O$ mesmo pode se dizer de "Dramatis Personae", parte das Notas em que são apresentadas as personagens no que se refere à função no enredo, características psicológicas, contradições, caráter, linguajar específico e movimento na trama.

Após essas sete partes, iniciam-se as notas explicativas de cada cena. Ao longo de 59 páginas, referindo-se a versos específicos numerados ao longo do texto, são apresentadas expressões próprias do idioma inglês, justificativas para traduções livres, padrões de repetição em outras peças de Shakpespeare, referências a outros textos, alusões a cantigas da época, escolhas estilísticas, formas "corretas" de entonação de determinados versos, trechos de especialistas, a edição específica escolhida para tradução em determinado trecho para reforçar um sentido, o significado de certas cenas, explanações de trocadilhos.

Posteriormente, Pennafort expõe algumas das obras consultadas para elaboração da tradução, e afirma ter se debruçado em estudos sobre o poeta, seu meio, suas fontes, o teatro do seu tempo, seu teatro e a peça em específico, enumerando algumas obras de referência sobre Shakespeare, sua biografia, gramática e léxico. Revela, em seguida, o quanto deve, para a realização de sua tarefa, às versões clássicas de dois célebres tradutores franceses: Guizot e François Victor-Hugo. Em português, aponta não conhecer outra tradução além da versão em prosa de Domingos Ramos, tratando-se mais de obra de vulgarização do que trabalho literário - tradução em que "Tanto lhe falta, aliás, em fidelidade, quanto lhe sobra em máo gosto [...]" (1940, p. 274). No Brasil, afirma que, além da tradução em prosa de Hamleto por Tristão da Cunha em 1933, não há traduções de Shakespeare dignas de valor literário, somente adaptações decalcadas de versões francesas e italianas - salvo os pequenos trechos de Hamleto, Othelo, Rei Lear e Romeu e Julieta traduzidos e adaptados em versos por Olavo Bilac.

Ao longo das Notas, Onestaldo de Pennafort traça um amplo quadro de referências para o leitor e ao mesmo tempo respalda a força de seu trabalho, trabalho este que implica estudo minucioso e erudição. Ele provém o leitor de balizas históricas, literárias e linguísticas, assumindo a mobilidade, as variantes e as transformações do texto shakesperiano, mas, ao mesmo tempo, selando um compromisso de fidelidade em relação a todo esse legado.

Por fim, para além do motivo para a tradução ter sido a incumbência do Ministério da Educação, o tradutor expõe as suas motivações pessoais apaixonadas, carregadas de tonalidades simbolistas:

“[...] as [...] razões profundas foram, por um lado, uma natural predilecção pelos poemas de amor - que outra cousa não é esta peça - e, por outro, um encantamento esthetico jamais arrefecido, e desde os longinquos tempos do deambular noctambulo da mocidade, pelo crepusculo matutino, hora entre todas mysteriosa e cheia de uma ineffavel poesia; hora de Julieta, hora de Romeu e Julieta. Cada obra de arte, e, em especial, cada obra literaria, tem o seu estado de espirito particular, o seu clima proprio, a que correspondem determinados aspectos da nature- 
za e a estes determinada hora. E assim como Macbeth, com os seus tres temas do somno, do sangue e do crime, é a tragedia da noite profunda, Romeu e Julieta é a tragedia da ante-manhã, dos primeiros albores do dia, dos primeiros "rubores de luz", desse instante indeciso e subtil em que já não é noite e ainda não é dia. [...] Quem já apreciou a indizivel belleza dessa hora de mysterio e de poesia e souber comprehender toda a significação que ella assume em Romeu e Julieta, terá lido o melhor commentario sobre a peça. (Pennafort, 1940, p. 276-277)

\section{Considerações Finais}

Se nas décadas anteriores era patente no Brasil o anonimato e a invisibilidade da tradução e do tradutor teatral (Rabetti, 2017), acreditamos que, a partir da década de 1940, seja possível vislumbrar um novo capítulo na história da tradução teatral no Brasil, ao menos no que se refere à políticas de publicação e projetos editoriais. Outras publicações de textos clássicos do período trazem o mesmo impulso com paratextos elucidativos acerca do lugar e da importância daquela peça no desenvolvimento teatral brasileiro, assim como, por vezes, acerca do próprio papel do tradutor nessa empreitada - a exemplo de Escola de maridos, por Jenny Klabin Segall (Molière, 1937). Para além da encomenda de companhias profissionais e da circulação de manuscritos e datiloscritos utilitários, as traduções em livros ganham força, se erigindo como partes de projetos nacionais, com maior ou menor força de monumentalização, e com objetivos e sentidos que transcendem a realização nos palcos, obviamente, sem excluir esse percurso.

Essa nova dimensão se dá, certamente, pelos impulsos modernizadores existentes no período, incluindo-se aí a intervenção estatal baseada em um projeto político- pedagógico, a reivindicação de associações de classe, o delineamento de políticas culturais, a atuação de grupos amadores, novas injunções sociais, além, é claro, de um impulsionamento do mercado editorial verificável desde a década de 1920. A relativa atribuição de importância à figura do tradutor, que é acompanhada pela solidificação de um modo de traduzir de alguma maneira preocupado com a "fidelidade" ao original (e essa ética pode ser legitimada diante do leitor em prefácios), ultrapassa, paulatinamente, uma cultura teatral tradutória que, herdeira de tradições antigas, se valia de "traduções livres", "versões", "imitações", "adaptações", o que também é resultado da introdução progressiva de uma lógica de direitos de autor. Evidentemente, isso precisa ser matizado pela importância atribuída a cada original. Romeu e Julieta, evidentemente, já era um monumento da cultura letrada ocidental, de modo que o projeto de sua tradução e publicação não poderia, naquele momento, invibilizar a figura do tradutor.

O fato de o primeiro volume da Coleção pretendida pela Comissão de Teatro Nacional ter sido lançado somente em 1940 (três anos após o inquérito), e de não haver, até o presente momento da pesquisa, indícios de um segundo volume, indica as descontinuidades dos projetos editoriais, que, muito provavelmente, esbarravam nas dificuldades em obtenção de verbas do Estado e no relativo desinteresse dos editores particulares. No entanto, acreditamos que há um paulatino aumento dos esforços de tradução. 
Encarando essas publicações como projetos editoriais, os paratextos podem ser fontes privilegiadas para o estudo das traduções teatrais, permitindo entrever disposições no ato tradutório. A pergunta "quais os protocolos de leitura presentes nos paratextos de Pennafort?" não encontra resposta simples, demandando um exercício de interpretação que muitas vezes passa por vias indiretas. São patentes, de todo modo, como analisado ao longo desse artigo, os direcionamentos a uma leitura que toma Romeu e Julieta e Shakespeare como incontornáveis no panorama de uma formação teatral e humanista; a tradução em versos como condição para a fidelidade a essa obra; o ato tradutório como mediador imperfeito, mas necessário e legítimo; o conhecimento das possíveis motivações do autor inglês para uma fruição mais completa; a explanação dos caminhos transnacionais pelos quais passa a tradução como fator de legitimidade. O que não esgota as possibilidades de outras leituras desse conjunto de dispositivos que são os protocolos de leitura contidos nos paratextos.

A condição de publicação, certamente, é o que garante a fixação desses paratextos. A respeito do estatuto do "teatro impresso", Véronique Lochert lança importantes considerações - com as quais finalizamos esse artigo - para se observar o texto de teatro à partir da "margem":

A publicação favorece a produção de notas anti-teatrais, fazendo ouvir a voz do autor e colocando em relevo os aspectos textuais da obra, em uma busca da dignidade literária que passa por aproximar-se de outros gêneros. O corpus heterogêneo constituído pelas notas que acompanham as peças impressas possui estreitas relações com o gênero do comentário (...).Desenvolvendo um discurso secundário que atrai o olhar do leitor para as margens, elas [as notas] colocam em questão a autonomia do texto e dão a imagem de uma obra fragmentada entre vários autores - poeta, editor, tradutor e mesmo atores, várias dimensões - poética, histórica, moral, religiosa e vários destinatários. Elas adaptam o texto à leitura $[\ldots] .{ }^{10}$ (Lochert, 2010, p. 27-28)

\section{Referências}

BANDEIRA, Manuel. Onestaldo, tradutor. In: BANDEIRA, Manuel. Andorinha, andorinha. Sel. e coord. Carlos Drummond de Andrade. Rio de Janeiro: J. Olympio, 1966. p.200-201.

CAMARGO, Angélica R. Em busca de uma política para o desenvolvimento do teatro brasileiro: as experiências da Comissão e do Serviço Nacional de Teatro (1936-1945). Rio de Janeiro, 2011.Dissertação (Mestrado) - História Social, UFRJ.

CHARTIER, Roger. Do Livro à Leitura. In: CHARTIER, Roger. (Org.). Práticas da leitura. Tradução de Cristiane Nascimento. São Paulo: Estação Liberdade, 1996. p. 77-105.

10 « La publication favorise la production de notes anti-théâtrales, faisant entendre la voix de l'auteur et mettant en relief les aspects textuels de l’oeuvre, dans une quête de dignité littéraire qui passe par le rapprochement avec d’autres genres. Le corpus hétérogène constitué par les notes qui accompagnent les pièces imprimées entretient d’étroites relations avec le genre du commentaire [...]. Développant un discours secondaire qui apppele le regard du lecteur dans la marge, elles [les notes] mettent en question l'autonomie du texte et donnent l'image d’une oeuvre éclatée entre plusieurs auteurs - poète, éditeur, traducteur et même acteurs, plusieurs dimensions - poétique, historique, morale, religieuse, et plusieurs destinataires. Elles adaptent le texte à la lecture [...]. » (tradução nossa) 
FONTANA, Fabiana Siqueira. Por um sonho de nação: Paschoal Carlos Magno e o Teatro do Estudante do Brasil. Rio de Janeiro, 2014.Tese (Doutorado) - Artes Cênicas, UNIRIO.

GENETTE, Gérard. Introdução. In: GENETTE, Gérard. Paratextos Editoriais. Tradução de Álvaro Faleiros. São Paulo: Ateliê Editorial, 2009. p. 9-20.

LOCHERT, Véronique. De la note à la didascalie: le texte dramatique vu depuis la marge. Revue d’ Histoire du Théâtre, Paris, 2010-I-II. № 245-246. p. 27-37, 2010.

MOLIÈRE. A escola dos maridos; O marido da fidalga. Tradução em versos e ilustrações a cores de Jenny Klabin Segall. Athena Editora, 1937.

O Govêrno e o Teatro. (folheto) Rio de Janeiro: Serviço Gráfico do Ministério da Educação e Saúde, 1937.

PENNAFORT, Onestaldo de. Introducção. In: SHAKESPEARE, W. Romeu e Julieta. Tradução integral, em prosa e verso, por Onestaldo de Pennafort. Rio de Janeiro: Ministério da Educação e Saúde, 1940. p. 11-15.

PENNAFORT, Onestaldo de. Notas.In: SHAKESPEARE, W. Romeu e Julieta. Tradução integral, em prosa e verso, por Onestaldo de Pennafort. Rio de Janeiro: Ministério da Educação e Saúde, 1940. p. 203-277.

RABETTI, M. L. Pois é...isso!: trânsitos e transações da tradução teatral. In: Congresso da Associação Brasileira de Pesquisa e Pós Graduação em Artes Cênicas, 9., 2017, Uberlândia. Anais... Uberlândia: UniversidadeFederal de Uberlândia, 2017. Disponível em: https://goo.gl/RQ8UA3. Acesso em: 20 maio 2019.

SHAKESPEARE, W. Otelo: o mouro de Veneza. Tradução de Onestaldo de Pennafort. Rio de Janeiro: Civilização Brasileira, 1956.

SHAKESPEARE, W. Romeu e Julieta. Tradução integral, em prosa e verso, por Onestaldo de Pennafort. Rio de Janeiro: Ministério da Educação e Saúde, 1940.

SÜSSEKIND, Pedro. Shakespeare: o gênio original. Rio de Janeiro: J. Zahar, 2008.

Recebido em: 20/06/2019

Aprovado em: 10/07/2019 